\title{
Development and inequalities
}

PIERRE SALAMA*

The rise in wages inequalities, whatever may be the level of development reached, is linked to the modernization of countries, a modernization percieved as a constraint in an ever more globalised world. This tendency is sometimes thwarted by sustained education policies and by restrictive government policies aiming at raising low wages. But as a tendency, it is stronger when countries increase their opening rate and modify the exports structures toward ever more sophisticated products. One can however see how much it is artificial to separate technology from exports in order to measure their respective weight on the rise of inequalities.

Keywords: Inequalities; globalization; modernization; structure of exportations; social policies.

JEL Classification: 01; F16; F4; J31.

In an article, which became a classic, Kuznets points out that throughout the development process in any given country, the evolution in income distribution takes the shape of an inverted U. At the beginning of the industrialization process, inequalities increase because peasants leave their farms to go to the cities. ${ }^{1}$ After a period of increase, inequalities stabilize and then decrease along with the marginalisation of the rural sector and the growth of industries. In the last twenty years this sequential evolution has not been verified: in most countries one can notice a more or less significant increase in inequalities; in some countries a relative stability; and in very few countries a slight yielding, whatever their level of development. ${ }^{2}$

Along with the globalization of cultural exchanges, mimicking the western way

* Professor of economics at the Paris XIII University. E-mail: pierresalama@gmail.com. Submitted: February 2009; Approved: April 2009.

${ }^{1}$ See Kuznets S. (1955): "Economic growth and economic inequality”, American Economic Review n 45.

${ }^{2}$ Le défi des inégalités, Amérique Latine/Asie: une comparaison économique, La Decouverte, web page: http://pagesperso-orange.fr/pierre.salama/. 
of life may lead to behaviour changes, the most qualified strata straining to reach the income equivalent that they would enjoy in developed countries. The average income in developing countries being lower, this implies major inequalities, higher than those in developed countries. Contrary to what happens in the least developed economies, developing economies export ever more products requiring skilled labour. But as this labour is generally insufficient in view of raising demand, wage increases are higher than those unskilled workers could hope for because they are less in demand, which generates increasing inequalities in wages. Can we then claim that openness is the main cause for increased inequalities? Can these inequalities be the cause of the development freeze in developing countries when they reach a certain threshold?

These are important questions. But let us not forget that other factors can impact the level and evolution of inequalities, such as public expenditure on education, social policies against poverty, and the development of the financial sector. In the scope of this paper, we cannot deal with them in detail for social policies often have little impact on income inequalities (even if they can sometimes be effective in fighting poverty) and because the financial sector is generally not highly developed in these countries. We can nevertheless note that in some Latin American countries, growing financialization distorts the distribution of the added value with a higher share for profits. Wages do not keep up with labour productivity, and since at the same time higher wages increase strongly, wage inequalities rise. The resulting weak domestic demand could curb any growth where a country does not enjoy a large population and if the degree of openness remains limited.

\section{INEQUALITIES AND GROWTH}

A. The evolution of income distribution is nowadays much more complex than as described by Kuznets, mainly because the countries are more in contact among themselves than in the past. In some developing countries inequalities tend to increase $^{3}$ and where they decrease, it's at the margin and from a high level. Birdsall ${ }^{4}$ remarks that the countries with a per capita income under US\$3000 (purchasing power parity, PPP) ${ }^{5}$ and with a Gini ${ }^{6}$ under 0.45 , show a slow down in the raise

\footnotetext{
${ }^{3}$ Certain economists, such as Dollar and Kraay, question this evolution and consider that there is on average, no increase in inequalities, except among wages and to the exception of China. See Dollar D. \& Kraay A. (2001): "Growth is good for the poor", working paper for the World Bank.

${ }^{4}$ Birdsall N. (2007): "Reflections on the macro foundations of the middle class in the developing world", Center of Global Development, working paper $n^{\circ} 130$.

${ }^{5}$ One can calculate an exchange rate of a so called purchasing power parity (PPP) in making sure that a dollar would have the same purchasing power in all countries. It is not therefore the official exchange rate in which goods are exchanged on the international market. The difference can be important, particularly in Asia.

${ }^{6}$ The GIni coefficient is an aggregate indicator of inequalities: the nearer it is to 1 , the higher are the
} 
of inequalities, up to a freeze, to the exception however of China in the 90s, when its per capita income was under US\$3000 (PPP). She notices that inequalities increase in the rural sector as well as in the urban sector. On the whole, from 1990 to 2004, middle classes ${ }^{7}$ show distinct evolutions: in Brazil, for instance, middle classes amounted to $18 \%$ of the population in 1990 and $29,5 \%$ in 2004, while they collected $25,2 \%$ and $34,8 \%$, respectively. In China (towns) these figures were respectively $0 \%$ and $31,5 \%$ on one side and on the other $0 \%$ and $38,5 \%$ (p. 19 , op.cit.). These two examples are telling of two distinct evolutions: a light relative "impoverishment" of the middle classes in Brazil (they earn more but they are far more numerous), while in China middle classes benefit from ever increasing inequalities - the Gini rose from 0.29 in 1990 to 0.44 in 2003.

Asian countries enjoy less inequalities than the levels found in Latin America. To the exception of today's China, and Thailand, their Gini coefficients are between 0.30 and 0.40 . In India and in China, inequalities are rising significantly. ${ }^{8}$ But one can also remark that some few countries, such as South Korea, do not show a rise, or only a slight one, in inequalities, those remaining at a low level (0.30). One can also observe that in some Latin American countries inequalities tend towards stabilization, and even towards a slight weakening in the last decade, even if from an extremely high level. ${ }^{9}$

Is the more or less higher raise of inequalities the result of growth and its volatility? ${ }^{10}$ The higher the growth, the stronger the social mobility. But contrary to what one would think, increased social mobility is not necessarily followed by a stabilization in inequalities as one can verify in confronting China's path to that of Korea.

B. With an average growth rate of $10 \%$ a year - as is more or less the case in Asia - the GDP doubles in only seven years. But if this rate is $2 \%$ a year - as in Latin

inequalities; the farther it is, the lower they are. This coefficient can apply either to the whole income, or only to the available income (after transfers and taxes), or still to wages only. The latter is more reliable for low incomes are difficult to assess (the level of self consumption and non monetary trade is hard to take into account) and it is the same with highest incomes (income tax returns are not very reliable especially when it is a question of dividend payments or interests received rarely accounted as income when they are automatically reinvested).

${ }^{7}$ The middle classes are defined by Birdstall as those who have an income per capita and per day calculated at the 1993 PPP exchange rate of US\$7,20 in 1990, and at the 2005 exchange rate of US\$10 PPP in 2004, and under the $9^{\text {th }}$ decile.

${ }^{8}$ See Asian Development Bank (2007): Inequality in Asia, key indicators. Philippines.

${ }^{9}$ See Humberto Lopez \& Perry (2008): “Inequality in Latin America, determinants and consequences”. Policy research, working paper $\mathrm{n}^{\circ} 4504$, World Bank, Washington. Inequalities lowered slightly in the 90s, for example, in Brazil and Mexico, while they rose in Colombia and Argentina. They dropped in the 2000s in Brazil following the increase in the minimum wage, and new social policy (family grant), but they remain at an extremely high level.

${ }^{10}$ There are several ways of measuring the volatility of growth: the standard deviation is often used as an indicator but one can also use the crisis frequency (negative growth rate), the frequency of the years when the growth rate is under $2 \%$. 
America - it takes 35 years for the GDP to double. In thirty five years the GDP is multiplied by thirty two in the first case, and by two in the second. The quantitative becomes qualitative and the recent debate over the distinction to be made between growth (quantitative) and development (qualitative) becomes significant.

To sustain a lasting growth at such high levels, a certain number of structural obstacles must be reduced or even the overtaken, such as obstacles in education, in ownership relations, in the quality of institutions, etc. In the case of China, radical changes are needed if growth is to be sustained, such as the implementation of laws on land ownership (and not only its usufruct), the consolidation of a health system, of a social security in a broad sense (retirement, workers protection) and, probably, the recognition of human and women rights, leading to fewer inequalities. If these qualitative aspects are not asserted, then the shortfall in development will constitute a freeze or at least a slow down for the growth, all the more when the present crisis forces changes in the growth pattern.

The scale of growth affects social mobility: the lower the growth, the weaker the mobility and a child raised in poverty has a high probability of remaining poor (unless he becomes a sportsman, a singer, or if he enters into politics or joins the criminal business, and he still has to be very gifted); on the contrary, the stronger the growth, the lower the probability for a poor child of remaining poor, ${ }^{11}$ which does not imply that inequalities decline since poverty is measured in absolute figures, while inequalities are measured in relative figures.

The level of growth depends at the same time on the investment rate, on the modernization of capital goods, and on labour skills. Advances in technology have a positive impact over growth but, according to econometric tests, they have a negative impact on income distribution, especially in developing countries. The main cause for the increase in inequalities would thus be the introduction of new techniques and, as a secondary cause, the opening of the economy. ${ }^{12}$ However, one can regard the two variables as not independent: the use of more and more sophisticated techniques, including partly in sectors protected from international competition, is the either direct or indirect result of competitive constraints imposed by the increase in international trade. The higher the growth rate and the stronger the productivity increase, the stronger the probability that inequalities will increase, unless income redistribution measures are undertaken. One could finally add that the penetration of new techniques leads to an "unequal and combined" development as pointed out by Parvus and later Trotsky at the beginning of the $20^{\text {th }}$ century, in countries at the dawn of their industrialization process - for their use is combined with more or less archaic kinds of labour. The use of modern techniques, expressing international constraints, would then generate more inequality in coun-

\footnotetext{
${ }^{11}$ It is possible to find a good presentation of the literature on this question in Humberto Lopez and Perry (op. cit.).

${ }^{12}$ See for example the works of Jaumotte F., Lall S. \& Papageorgiou (2008): "Rising income inequality: technology or trade and financial globalization”, IMF, working paper n 185.
} 
tries undergoing a recent industrialization, such as China, than in countries with a more ancient industrialization, such as Brazil.

Growth is not only weaker in Latin America than in Asia, but it is also more irregular and volatile. The volatility has negative effects on income distribution: the higher it is, the stronger the probability of an increase in inequalities. Bourguignon (2008) remarks that "the instability has heavy social repercussions. Major economic crises have harmful effects [...] they tend to produce a permanent increase in inequalities and poverty $[. .$.$] given that the poorest are disproportionately affected$ by the adjustments" (p. 15). ${ }^{13}$ As it happens, this volatility is high in developing countries and more particularly in Latin America. Zettelmeyer J. (2006 $)^{14}$ shows that since 1950 the periods when growth per capita exceeds $2 \%$ a year were more numerous in Asia than in Latin America, and, above all, lasted longer. According to him, since 1950 there were 10 periods of growth above $2 \%$ per capita in Latin America, versus 11 in Asia, their average length being in the first case of 13,9 months, but reaching 26,1 months in the second; finally in 30\% of the cases these phases of development exceed 15 years in Latin America against $73 \%$ in Asia. Solimano and Soto $(2005)^{15}$ also notice that the percentage of years of crises (negative growth rate) in the period 1960-2002 is 42\% in Argentina, 20\% in Brazil but only $7 \%$ in South Korea and 5\% in Thailand. Finally, the UN Economic Commission for Latin America in its 2008 report shows that the standard deviation of the growth rate from 1991 to 2006 is particularly high in Argentina (6.29), lower in Brazil (2.02) and Mexico (3.05). One can then consider that, unfortunately with no risk of being mistaken, the present crisis has and will have particularly negative effects on the more vulnerable, precisely the poor, and it will widen the inequality gap.

\section{GLOBALIZATION AND INEQUALITIES}

A. In 1993, the World Bank published a report intended at deciphering the causes of the Asian "miracle" and found them to be free trade. The reasoning was based on econometric tests: those countries showing the strongest growth rate where those with the highest degree of openness and lowest inequalities. Asia was therefore set against Latin America and Africa. Conclusions were drawn: on the one hand, opening to international trade should increase the growth rate, provided however that the country - "poor" in qualified labour and in capital, but "rich" in unskilled labour-specialize according to their relative wealth in production fac-

\footnotetext{
${ }^{13}$ Bourguignon F. (2008): "Stability, Security and Development: an introduction”, Review of the Economy of Development.

${ }^{14}$ Zettelmeyer J. (2006): "Growth and Reforms in Latin America: a Survey of Facts and Arguments", working paper WP/06/210 IMF, Washington.

${ }^{15}$ Solimano A \& Solo R. (2006): "Economic Growth in Latin America in the late of $20^{\text {th }}$ century: evidence and interpretation”, Cepal, Macroeconomia del Desarollo series, $\mathrm{n}^{\circ} 33$.
} 
tors; on the other hand, free trade should generate a decrease in inequalities because demand for unskilled labour should increase while the demand for skilled labour should decrease.

This idyllic approach has been strongly criticized, first because it was noticed that inequalities increased while customs were disarmed (Argentine, China) and then - from a theoretical point of view- because this would lead to a confusion between openness (with export led growth) and free trade ${ }^{16}$ and finally because pure theory relies on untenable hypotheses. Dean Baker could thus assert: "the role of economists in trade debate is especially pernicious because there is no area of economics in which economists have been less honest about their models show. They have consistently exaggerated the benefits they are predicted by standard trade models". ${ }^{17}$

Is it because the unprecedented increase, during the last decades, in exports of manufactured goods is particularly important in many developing countries that inequalities increase? Is it because the structure of exports is evolving toward increased sophistication and skilled labour employment that wage inequalities are on the rise? The question arises of the responsibility of globalization, but not as defined by the neoclassical school.

The discussion developed when Mexico, a low wages country, joined NAFTA. ${ }^{18}$ Several economists and trade unionists fear that the competition from low wages countries will lead to growing inequalities in rich countries. In an article that also became a classic, Krugman ${ }^{19}$ holds the opposite view from these fears and demonstrates that globalization is not responsible for the raise in inequalities, or only marginally. His reasoning relies on the light weight (in relation to GDP) of manufactured goods imports, on the relative weakness of those coming from Third World countries, and of the relative decrease of manufacture industries compared to the increasing weight of services in the GDP. Later, following both numerous critics and new calculations upgrading the impact of globalization on the raise of inequalities, ${ }^{20}$ Krugman $^{21}$ moderates his diagnosis when, on the one hand, the weight of emergent economies on US imports became more important than that of

\footnotetext{
16 The opening is compatible with an industrial policy. The literature is extensive, for a detailed account see our book: "Le défi des inégalités, op. cit., chapter 3: "Passivité versus volontarisme, l'ouverture revisité".

${ }^{17}$ Baker D. (2008): “Trade and inequality: the role of economists”, in Real World Economic Review, $\mathrm{n}^{\circ} 45$.

${ }^{18}$ NAFTA is a free trade agreement between the United States, Canada and Mexico.

${ }^{19}$ This article has been published in a collection of articles in Krugman P. (2008, last edition: La mondialisation n'est pas coupable, vertus et limites du libre échange, Éditions La Découverte, Paris, see pages 47 to 61 .

${ }^{20}$ One can for instance see the article from Bivens J. (2007): "Globalization, American wages and inequality, past, present and future”, Economic Policy Institute, working paper.

${ }^{21}$ Krugman P. (2008): “Trade and wages reconsidered”, mimeo, published in his web pages.
} 
developed countries, and when, on the other hand, imports structure (and therefore exports from emergent economies and more particularly from China) strongly evolved in favour of sophisticated products. If we take into account the first ten US commercial partners, the differential of hourly costs in relation to that of US, balanced by their weight on trade, fell from $81 \%$ in 1980 to $65 \%$ in 2005 . This evolution weights down on North American wages and has its share in increasing inequalities.

B. In developing countries, growth in exports takes place at a different pace according to each country, strong in some Asian economies, and slower in others.

More precisely, global trade has grown twice faster than global GDP. According to WTO, global exports rose on average from 1998 to 2008 by $5.8 \%$ a year, and the global GDP by $3 \% .{ }^{22}$ The weight of exports and imports on global GDP is therefore increased. According to IMF database, the percentage of global exports in relation to global GDP, which was $27 \%$ in 1986 , rose to $36 \%$ in 1996 , and then up to $50 \%$ in 2006 . However, this increase in exports is irregular: in 2000 the increase in global exports reached above $10 \%$, while it was slightly negative in 2001 ; in 2007 it reached 6\%, in 2008, 2\%, and in 2009, according to WTO forecasts, it should be $9 \%$ (op. cit.). All countries do not open at the same pace.

The share of goods and services exports from China in the global trade was $1,5 \%$ in 1988 and $8,9 \%$ in 2008. For Brazil, during the same periods, it was respectively $1 \%$ and $1,2 \% .{ }^{23}$ The difference is important: both economies have known an increased opening process, but at very different speeds. The opening of Brazil to the global economy has been accomplished at the same pace than that of global exports. China opened at a much faster pace.

The relation between trade increase and growing inequalities is more complex than was often thought. Certain countries show a rising opening of their economies and an outburst of inequalities (China, India), while very few others, remain relatively closed and undergo the same evolution in income distribution (Nepal), finally some, as in Latin America, have opened themselves to the global economy in the 90s and 2000s but at a moderate pace, and show either a light lowering in inequalities (Brazil) or a slight increase, to the exception however of Argentina, where liberalisation of the economy was followed by a very pronounced rise in inequalities. Finally, one can observe that a few countries, such as South Korea, are particularly open to international trade but do not show any increase - or only slight - in inequalities, and these remain limited.

Taking into account only the opening rate to international trade and the evolution of this rate is not enough. The relation between globalization, development and increased openness becomes more explicit when one analyses the exports structure as well. This structure has deeply evolved. It is generally known that the rise in exports of high and medium technology products is much faster in developing

\footnotetext{
${ }^{22}$ WTO: "World Trade in 2008 and Prospect to 2009", press release 554, March 24, 2009, Genève.

${ }^{23}$ WTO and OECD (2008): Globalization and Emerging Economies, Paris.
} 
countries than in developed countries: $16,5 \%$ in the first case and $7,3 \%$ in the other, from 1980 to $2000 .{ }^{24}$ Not all developing countries go through these changes, far from it. These are concentrated in some countries, almost exclusively Asian. Certainly an important part of these exports of sophisticated products is more the result of a statistic illusion than of an economic reality, when these are products from assembling industries with low added value and employing less costly and unskilled labour. But when the added value rises, the sophistication generally rises, and the share of skilled labour in total labour is increased. The range of qualifications widens then, and inequalities among wages tend to grow, even if these skilled workers earn less than their counterparts in developed countries.

This tendency can be however thwarted if, parallel to a specialization on products of high and medium technology, the supply of skilled labour is considerably increased due to a sustained education policy. Supply and demand of labour, skilled and unskilled, change then harmoniously and the raise of incomes is not necessarily translated into a rise in wages inequalities. This seems to be the case in South Korea. The tendency to an increase in wages inequalities can also be thwarted in the case when the country does not substantially modify the structure of its exports of high and medium technology products, but continues to export essentially low and medium technology products and primary goods. In this case, the demand for skilled labour is lower than in the previous case. The tendency to increased inequalities, is relatively weaker, and can equally be thwarted by two factors: noticeably raising the minimum wage (far above the rate of average income increase), and improving education policies. The latter can then lead to a relative surplus in the supply of skilled labour with respect to an insufficient demand from entrepreneurs finding it difficult to specialize in high technology products. This relative surplus is therefore responsible for the downgrading of a part of the skilled labour. This seems to be the case in Brazil. ${ }^{25}$

\section{CONCLUSION}

The rise in wages inequalities, whatever may be the level of development reached, is linked to the modernization of countries, a modernization perceived as a constraint in an ever more globalised world. This can be explained by technology and by opening. As a general rule, whether or not the countries are developing, the first factor seems to better explain the rise in inequalities than the second factor, and this particularly in the developing countries. This tendency is sometimes thwarted by sustained education policies and by restrictive government policies aiming at

\footnotetext{
${ }^{24}$ Lall S. (2004): "Reinventing Industrial Strategy: the Role of Government Policy in Competitiveness”, G-24 Discussion Paper Series, United Nations, New York.

${ }^{25}$ For more precision, see Kliass P. \& Salama P. (2008): “A globalização no Brasil: responsável ou bode expiatório”, Revista de Economia Política, vol. 38, n³8, São Paulo.
} 
raising low wages. But as a tendency, it is stronger when countries increase their opening rate and modify the exports structures toward ever more sophisticated products. One can however see how much it is artificial to separate technology from exports in order to measure their respective weight on the rise of inequalities. The lasting increase of manufactured goods exports can not effectively take place unless the countries successfully carry out changes in their industrial network, modernizing it in order to fit positively into the global market in dynamic products with high demand elasticity (in relation to income).

Improving techniques and the ability to raise the opening rate are linked. It is therefore modernization that is responsible for the tendency towards growing wages inequalities. And yet modernization is a "survival condition". The dilemma between modernization and increasing inequalities might be eliminated by a tax policy and by policies supporting the lowest wages up to the required level. Or, the probably most important reason explaining the persistence of strong inequalities - or else the inability to slow down their raise - is the inadequacy of social policies in most developing countries. Some simple data can point this out. According to OECD in 2006, the Gini coefficient in Latin America is on average 0.52 and when one takes into account taxes and social transfer, it decreases by only two points, while in Europe the same coefficient falls from 0.46 to $0.31^{26}$. The difference is telling and confirms the idea that growth can only be durable if it is thought in terms of development. Then, and only then, inequalities will be reduced, both in income and in access to rights (health, education, workers protection and justice). In democratic developing countries (which is far from being the general rule), social citizenship can then come closer to political citizenship. With the deepening of the current crisis, the fight against the increase in social inequalities, by revised social policies, becomes a demand not only economical but also and above all ethical.

${ }^{26}$ OCDE (2008): Latin American Outlook. 